polarography has, to my knowledge, received little attention.

Physical Chemistry Laboratory,

G. Russeli

Northern Polytechnic,

Holloway,

London, N.7.

1 Tanford, C., J. Amer. Chem. Soc., 74, 211 (1952).

2 Tanford, C., J. Amer. Chem. Soc., 73, 2066 (1952).

${ }^{3}$ Saroff, H. A. and Mark, H. J., J. Amer. Chem. Soc., 75, 1420 (1953)

4 Rao, M. S. N., and Lal, H., J. Amer. Chem. Soc., 80, 3222 (1958).

- Kolthoff, I. M., and Lingane, J. J., Polarography (Interscience, 1952).

\section{Annealing of Chemical Radiation Damage by Compression}

IT has already been reported that defects generated by compression accelerate the thermal annealing of the chemical damage in irradiated erystals ${ }^{2}$. The work recorded here indicates that compression directly induces recombination of the damage fragments.

Measurements were made on $\gamma$-irradiated lead nitrate crystals. Data concerning material, irradiation and analytical procedure have already been described ${ }^{1,2}$. The crystals were compressed with an Amsler machine in the range 0-20 tons/in. ${ }^{2}$. The fraction annealed by compression was 0.141 under 10 tons/in. ${ }^{2}$ and $0 \cdot 181$ under 20 tons/in. ${ }^{2}$. Crushing ${ }^{3}$, which also enhances thermal annealing, produced only a small recovery of $0 \cdot 048$.

S. R. Mohanty

S. R. UPADHYAY

Department of Chemistry,

Banaras Hindu University, Varanasi,

India.

${ }^{2}$ Mohantx, S. R., and Upadhyay, S. R., Nature, 199, 169 (1963)

'Mohanty, S. R., and Upadhyay, S. R., J. Inorg. Nuclear Chem., 25, 309 (1963).

${ }^{3}$ Mohanty, S. R., and Upadhyay, S. R., Indian J. Chem., 1, 456 (1963).

\section{Phase Diagram of the Vanadium Pentoxide- Borax System}

As reported previously ${ }^{1}$, investigations have been carried out on the vanadium pentoxide-borax system. Differential thermal analysis constituted the first part of the investigations. These measurements were made with a special device for differential thermal analysis's. The samples were prepared from chemicals of analytical grade. The temperature and the rate of melting of the mixtures were chosen so as to attain complete clarification. The gases formed during the melting procedure were tested by a method described in a previous paper ${ }^{3}$, but, apart from the crystal water liberated, no other gas; thus no oxygen was detected, proving that during the melting process, no liberation of the latter had taken place. The samples prepared were worked in the manner described elsewhere ${ }^{4}$.

The compositions of the samples, as characterized by their borax contents, are given in Table 1. The results of the differential thermal analysis are shown in Fig. 1.

$\begin{array}{cc}\begin{array}{c}\text { Table 1. } \\ \text { Sample }\end{array} & \begin{array}{c}\text { Borax Contents } \\ \text { Borax content } \\ \text { No. }\end{array} \\ 1 & \text { (wt. \%) } \\ 2 & 3 \cdot 9 \\ 3 & 7 \cdot 9 \\ 4 & 12 \cdot 0 \\ 5 & 14 \cdot 0 \\ 6 & 16 \cdot 1 \\ 7 & 20 \cdot 4 \\ 8 & 24 \cdot 8 \\ 9 & 34 \cdot 0 \\ 10 & 43 \cdot 5 \\ 11 & 53 \cdot 6 \\ 12 & 64 \cdot 2 \\ 13 & 75 \cdot 5 \\ & 87 \cdot 4\end{array}$

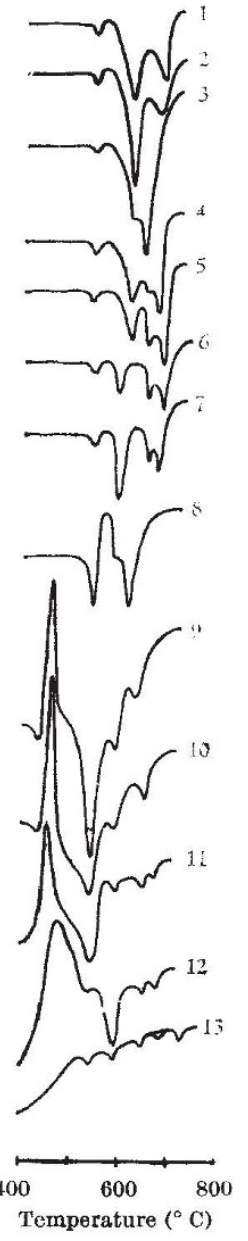

Fig. 1

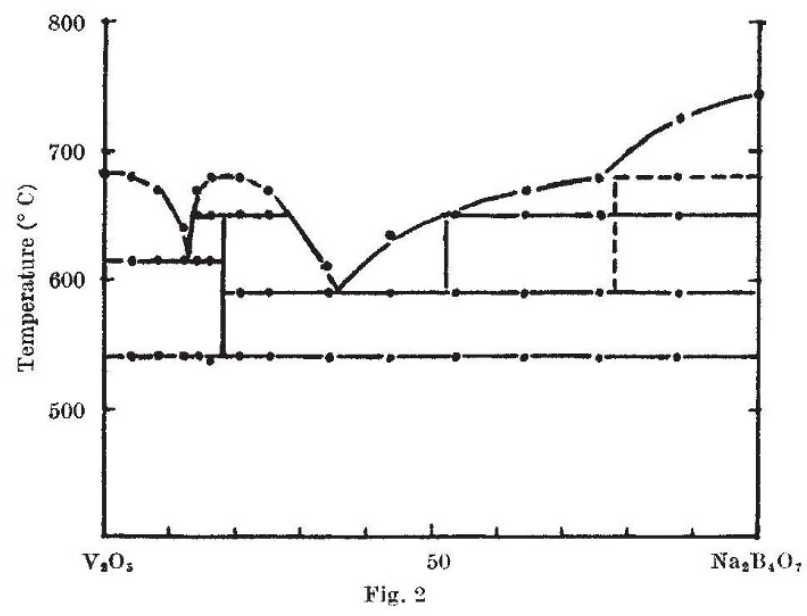

Curves 9, 10, 11 and 12 show a marked exothermal effect at $500^{\circ} \mathrm{C}$, which, however, does not appear in curves 12 and 13. Curve 13 indicates a decrease in the magnitude of the heat effects, owing to the high borax content. The phase diagram of the vanadium pentoxide-borax system. shown in Fig. 2 is plotted on the basis of the qualitative evaluation of X-ray investigations (based on the X-ray analysis of $\mathrm{T}$. Horvath) and the diagrams of differential thermal analysis, without a quantitative evaluation of the $\mathrm{X}$-ray diagrams. According to this phase diagram, the system is characterized by two eutectic compositions, and three compounds are to be expected to exist. It becomes 